\title{
Dietary Patterns and Further Survival in Japanese Centenarians
}

\author{
Kenichiro SHImizu ${ }^{1,2}$, Sumie TAKEdA ${ }^{3}$, Hiroyasu NojI ${ }^{3}$, Nobuyoshi Hirose ${ }^{2}$, Yoshinori EbIHARA ${ }^{2}$, Yasumichi Arai ${ }^{2}$, \\ Michiyo HAMAmatsu $^{2}$, Susumu NAKAZAWA ${ }^{2}$, Yasuyuki Gondo ${ }^{4}$ and Kanoko KonIsHI ${ }^{5}$ \\ ${ }^{1}$ Health Care Center, Shoko-Chukin Bank, 2-10-17 Yaesu, Chuo-ku, Tokyo 104-0028, Japan \\ ${ }^{2}$ Division of Geriatric Medicine, Department of Internal Medicine, Keio University School of Medicine, Tokyo 160-8582, Japan \\ ${ }^{3}$ Department of Clinical Nutrition, Keio University Hospital, Tokyo 160-8582, Japan \\ ${ }^{4}$ Tokyo Metropolitan Institute of Gerontology, Tokyo 173-0015, Japan \\ ${ }^{5}$ Keio Junior College of Nursing, Tokyo 160-8582, Japan
}

(Received November 1, 2002)

\begin{abstract}
Summary We have previously reported that centenarians (persons $\geqq 100$ y old) in Tokyo prefer dairy products. Dietary preferences may be associated with longevity. The aim of the present study was to investigate the relationship between dietary patterns and further survival in centenarians. During 1992-1999, we examined the dietary practices of 104 centenarians ( 29 men and 75 women; mean age, $100.3 \pm 0.9 \mathrm{y}$ ) who lived in the Tokyo metropolitan area. Dietary patterns were classified by $k$-means cluster analysis. As clinical co-variables, we considered activities of daily living, cognitive function, nutritional status, presence of important disease, gender, and age at the time of the initial survey. Survival data were recorded yearly until 2001, and then tested with Kaplan-Meier analysis and the log rank statistic. Four dietary patterns were identified: a pattern preferring vegetables $(n=33)$, a pattern preferring dairy products $(n=26)$, a pattern preferring beverages $(n=10)$, and a pattern preferring cereals $(n=35)$. No clinical variables differed between the four dietary patterns. In 2001, 28 centenarians were still alive. The survival rate for those preferring dairy products was the highest of the four dietary patterns; in particular, being significantly higher than the pattern preferring beverages $(p=0.048)$. A dietary pattern preferring dairy products was associated with increased survival in Tokyo-area centenarians.
\end{abstract}

Key Words dietary patterns, dairy products, centenarian, survival analysis

At least 15,000 people aged over 100 years, i.e. centenarians, presently live in Japan. Centenarians are considered a group that has achieved successful aging; their dietary habits may provide clues for late-life health. We have previously reported that centenarians in the Tokyo metropolitan area preferentially consume dairy products as compared to regionally matched elderly or middle-aged controls (1). According to a longitudinal study in Koganei City, Tokyo, an elderly cohort drinking large amounts of milk was at lower risk for death during follow-up (2). Dairy products could be associated with longevity. We therefore investigated the relationship between dietary patterns and further survival in centenarians.

\section{SUBJECTS AND METHODS}

Subjects. A total of 104 centenarians (29 men and 75 women; $100-105 \mathrm{y}$; mean age, $100.3 \pm 0.9 \mathrm{y}$ ) who lived in the Tokyo metropolitan area constituted the study subjects: 18 centenarians were recruited in 1992, 6 in 1993, 8 in 1994, 7 in 1995, 25 in 1996, 29 in 1997, 7 in 1998, and 4 in 1999. We examined their dietary practices at the time of the initial survey. Informed consent was obtained from the centenarians or their representatives.

E-mail: shimizu_kenichiro@1986.jukuin.keio.ac.jp
Evaluation of clinical status. Our medical team, which consisted of a doctor specializing in geriatric medicine, an educational nurse, a trained dietitian, and an experienced psychologist, visited centenarians to assess their physical and mental activities, use of medication, and past medical history as well as dietary practices. Activities of daily living (ADL) were assessed with respect to toilet care, eating, dressing, grooming, walking, and bathing using a modified Lawton's scale (3). Subjects were scored from 0 (completely dependent) to 19 points (completely independent). Cognitive function was classified semiquantitatively into five categories based on the clinical dementia rating (4) (CDR) of stage 0 (normal), stage 0.5 (subnormal), stage 1 (mildly demented), stage 2 (moderately demented), or stage 3 (severely demented). For evaluation of nutritional status, serum albumin concentrations were measured with an auto-analyzer (model 7170; Hitachi Instruments, Ibaraki, Japan).

We recorded the survival of study subjects yearly based on residence registration until 2001. In the present study, survival duration was semiquantified as follows: for example, for a centenarian recruited in 1996, the duration was determined as $0.5 \mathrm{y}$ if the centenarian was no longer registered in 1997; 1 year if registered until 1997 but not in 1998; 2 y if registered until 1998 but not in 1999; 3 y if registered until 1999 but not in 
2000; 4 y if registered until 2000 but not in 2001; or 5 $\mathrm{y}$ if still registered in 2001.

Analysis of dietary data. Contents of the diet, including snacks and beverages, were recorded for three successive days by the caregiver. Data concerning diet were analyzed using NUT Ver. 40 software (Human Science Laboratory, Shiga, Japan). (Note: This software is based on the 4th ed. Japanese Food Composition Table.) Dietary items were classified into 18 groups (5): cereals, potatoes \& starches (abbr. potatoes), sugars \& sweeteners (abbr. sugar), confectioneries (abbr. sweets), fats and oils (abbr. fats), nuts \& seeds (abbr. nuts), legumes, fishes \& shellfishes (abbr. fish), meats, eggs, dairy products, vegetables, fruit(s), mushrooms, algae, beverages including alcohol, seasonings \& spices (abbr. seasonings), and prepared or processed foods (abbr. processed foods). To classify dietary patterns, we considered the relative intake of each food group (a ratio of the intake of a given food group to total food intake) because absolute intake could be influenced by body size.

Classification of dietary patterns. We have previously reported on four dietary patterns of 222 subjects of various ages: a pattern preferring beverages, a pattern preferring vegetables, a pattern preferring cereals, and a pattern preferring dairy products (1). We therefore classified the dietary practices of centenarians into these four patterns by use of $k$-means cluster analysis based on the relative intake of each food group (6).

Survival analysis. Survival curves for each dietary pattern were compared with Kaplan-Meier analysis (7) and the log rank statistic. Clinical variables capable of influencing survival data were compared between the dietary patterns.

Statistics. Statistical analyses were performed using Statistica software (StatSoft, Tulsa, OK, USA). Intergroup means were compared by an analysis of variance (ANOVA) followed with Scheffe's multiple comparison. Differences in frequencies were tested by the chisquared test. Results are presented as the mean \pm SD. $p$ values of $<0.05$ were considered significant.

\section{RESULTS}

\section{Clinical status in centenarians}

The following important diagnoses were present in the centenarians: hypertension and cardiovascular disease (29 individuals), chronic lung disease ( 8 individuals), cerebral atherosclerosis ( 5 individuals), impaired glucose tolerance ( 1 individual), and femoral fracture (9 individuals).

ADL scores ranged from 0 to 19 points (mean 12.6 \pm 6.0 ), while CDR stages ranged from 0 to 3 (mean $1.1 \pm 1.2$ ). Serum albumin concentrations were measured only in 50 subjects (mean $34.7 \pm 4.7 \mathrm{~g} / \mathrm{L}$; range 23 to $42 \mathrm{~g} / \mathrm{L}$; normal range 38 to $52 \mathrm{~g} / \mathrm{L}$ ).

In 2001, 28 of the 104 centenarians were still living (mean follow-up period $4.25 \pm 1.08 \mathrm{y}$ ), while 76 centenarians had died (mean survival duration $1.88 \pm 1.39 \mathrm{y})$.

\section{Classification of dietary patterns}

Table 1 shows the four dietary patterns: pattern preferring vegetables $(n=33)$, pattern preferring dairy products $(n=26)$, pattern preferring beverages $(n=10)$,

Table 1. Dietary patterns of centenarians.

\begin{tabular}{|c|c|c|c|c|c|}
\hline & $\begin{array}{l}\text { Vegetables } \\
\text { pattern } \\
(n=33)\end{array}$ & $\begin{array}{l}\text { Dairy products } \\
\text { pattern } \\
(n=26)\end{array}$ & $\begin{array}{c}\text { Beverages } \\
\text { pattern } \\
(n=10)\end{array}$ & $\begin{array}{l}\text { Cereals } \\
\text { pattern } \\
(n=35)\end{array}$ & $\begin{array}{c}\text { Reference* } \\
\text { value }\end{array}$ \\
\hline Cereals (\%) & $24.0 \pm 5.7^{\mathrm{a}}$ & $19.1 \pm 7.5^{b}$ & $22.6 \pm 6.9^{c}$ & $38.9 \pm 7.6^{a, b, c}$ & 20.2 \\
\hline Potatoes (\%) & $3.3 \pm 2.3$ & $2.3 \pm 2.9$ & $3.2 \pm 2.3$ & $3.0 \pm 2.6$ & 4.9 \\
\hline Sugar $(\%)$ & $1.0 \pm 0.5^{\mathrm{d}}$ & $0.8 \pm 0.5^{\mathrm{e}}$ & $1.4 \pm 0.9^{\mathrm{e}, \mathrm{f}}$ & $0.6 \pm 0.3^{\mathrm{d}, \mathrm{f}}$ & \\
\hline Sweets $(\%)$ & $4.6 \pm 5.9$ & $3.9 \pm 5.9$ & $3.3 \pm 2.5$ & $4.7 \pm 3.8$ & 4.9 \\
\hline Fats $(\%)$ & $0.4 \pm 0.5$ & $0.3 \pm 0.4$ & $0.3 \pm 0.4$ & $0.4 \pm 0.4$ & 0.6 \\
\hline Nuts (\%) & $0.07 \pm 0.11$ & $0.05 \pm 0.10$ & $0.05 \pm 0.11$ & $0.02 \pm 0.04$ & n.a. \\
\hline Legumes (\%) & $4.6 \pm 2.8$ & $4.2 \pm 2.7$ & $4.6 \pm 3.8$ & $5.8 \pm 3.4$ & 7.8 \\
\hline Fish $(\%)$ & $5.5 \pm 3.4$ & $3.9 \pm 2.8$ & $4.9 \pm 1.8$ & $5.6 \pm 2.9$ & 7.1 \\
\hline Meats (\%) & $3.4 \pm 2.3^{g}$ & $1.8 \pm 1.7^{\mathrm{g}}$ & $2.4 \pm 1.6$ & $2.2 \pm 2.1$ & 2.3 \\
\hline Eggs $(\%)$ & $4.0 \pm 2.9$ & $2.9 \pm 1.9$ & $3.9 \pm 2.2$ & $3.3 \pm 3.1$ & 5.0 \\
\hline Dairy products $(\%)$ & $12.2 \pm 6.1^{\mathrm{h}, \mathrm{k}}$ & $29.5 \pm 13.3^{\mathrm{h}, \mathrm{i}, \mathrm{j}}$ & $10.9 \pm 6.3^{\mathrm{i}}$ & $5.7 \pm 5.5^{\mathrm{j}, \mathrm{k}}$ & 12.1 \\
\hline Vegetables $(\%)$ & $20.1 \pm 7.6^{1, \mathrm{~m}}$ & $11.6 \pm 7.0^{1}$ & $10.0 \pm 4.4^{\mathrm{m}}$ & $15.7 \pm 5.2$ & 15.5 \\
\hline Fruit (\%) & $11.3 \pm 6.9$ & $12.3 \pm 10.1$ & $8.1 \pm 5.5$ & $7.6 \pm 5.0$ & 12.7 \\
\hline Mushrooms (\%) & $0.5 \pm 0.5$ & $0.2 \pm 0.4$ & $0.2 \pm 0.3$ & $0.4 \pm 0.6$ & n.a. \\
\hline Algae $(\%)$ & $0.3 \pm 0.3$ & $0.3 \pm 0.4$ & $0.3 \pm 0.5$ & $0.3 \pm 0.2$ & 0.9 \\
\hline Beverages (\%) & $1.3 \pm 2.9^{\mathrm{n}}$ & $3.1 \pm 4.5^{\circ}$ & $21.5 \pm 8.8^{\mathrm{n}, \mathrm{o}, \mathrm{p}}$ & $2.4 \pm 4.2^{\mathrm{p}}$ & 6.1 \\
\hline Seasonings (\%) & $2.3 \pm 0.9^{q}$ & $1.5 \pm 1.0^{\mathrm{q}}$ & $1.9 \pm 0.9$ & $2.0 \pm 1.0$ & n.a. \\
\hline Processed foods (\%) & $1.1 \pm 4.3$ & $2.2 \pm 6.0$ & $0.5 \pm 1.3$ & $1.4 \pm 3.3$ & 0.3 \\
\hline
\end{tabular}

Values are presented as the mean \pm SD. Means were compared by ANOVA followed with Scheffe's test. Superscripts indicate that differences of values between the same symbols are statistically significant (e.g., intake of cereals between the vegetables pattern and cereals pattern show a significant difference, $p<0.001$ ). d, e, g, k, q: $p<0.05$, f: $p<0.01, \mathrm{a}, \mathrm{b}, \mathrm{c}, \mathrm{h}, \mathrm{i}, \mathrm{j}, \mathrm{l}, \mathrm{m}, \mathrm{n}, \mathrm{o}$, p: $p<0.001$.

* 220 centenarians, Japan overall (cited from ref. 8). n.a., not available. 
Table 2. Clinical variables in each dietary pattern.

\begin{tabular}{lccrr}
\hline & $\begin{array}{c}\text { Vegetables } \\
\text { pattern } \\
(n=33)\end{array}$ & $\begin{array}{c}\text { Dairy products } \\
\text { pattern } \\
(n=26)\end{array}$ & $\begin{array}{c}\text { Beverages } \\
\text { pattern } \\
(n=10)\end{array}$ & $\begin{array}{c}\text { Cereals } \\
\text { pattern } \\
(n=35)\end{array}$ \\
\hline Age (y) & $100.2 \pm 0.4$ & $100.5 \pm 1.3$ & $100.3 \pm 0.7$ & $100.4 \pm 1.0$ \\
ADL (points) & $11.3 \pm 5.8$ & $13.1 \pm 6.51$ & $2.6 \pm 6.3$ & $13.2 \pm 6.3$ \\
CDR (stages) & $1.2 \pm 1.3$ & $0.9 \pm 1.1$ & $1.0 \pm 1.1$ & $1.3 \pm 1.3$ \\
ALB (g/L)* & $35.2 \pm 3.3$ & $34.7 \pm 6.5$ & $32.7 \pm 3.3$ & $35.0 \pm 5.0$ \\
\hline
\end{tabular}

Values are presented as the mean \pm SD. Means were compared by ANOVA followed with Scheffe's test. Clinical variables did not differ among the four dietary patterns. Age, age at the time of the initial survey; ADL, activities of daily living; CDR, clinical dementia rating; ALB, serum albumin concentration.

* Measured in 17/33,11/26, 7/10, and 15/35, respectively.

Table 3. Gender difference in each dietary pattern.

\begin{tabular}{lccccc}
\hline & & $\begin{array}{c}\text { Vegetables } \\
\text { pattern }\end{array}$ & $\begin{array}{c}\text { Dairy } \\
\text { products } \\
\text { pattern }\end{array}$ & $\begin{array}{c}\text { Beverages } \\
\text { pattern }\end{array}$ & $\begin{array}{c}\text { Cereals } \\
\text { pattern }\end{array}$ \\
\hline Men & $n$ & 7 & 9 & 6 & 7 \\
Women & $n$ & 26 & 17 & 4 & 28 \\
\hline
\end{tabular}

Relationship between gender and dietary patterns was investigated by $\chi^{2}$ test. Gender differences were not observed among the four dietary patterns $\left(\chi^{2}(\mathrm{df}=3)=7.5\right.$, $p=0.06)$.

and pattern preferring cereals $(n=35)$. Centenarians that preferring vegetables consumed relatively large amounts of meat, while intake of fruit tended to be high for subjects that preferred vegetables and dairy products. The subjects that preferred beverages also showed a high intake of sugar, whereas the consumption of vegetables by those that preferred cereals was second only to that for those that preferred vegetables. For comparison, dietary practices of 220 centenarians reported in Japan $(8)$ are presented in Table 1.

Tables 2-4 compare clinical variables between dietary patterns. No significant differences were observed with respect to age at the time of the initial survey, ADL scores, or CDR stages. Serum albumin concentrations, although not statistically significant, tended to be lower for the centenarians that preferred beverages. More men preferred beverages than women, while women preferred more in all other groups. However, gender distribution differences were not evident. For those that preferred dairy products, centenarians without major diseases far exceeded those with overt disease, but no statistical association was indicated between present illness and dietary patterns.

Table 5 summarizes the daily intake of energy and nutrients in each dietary pattern. For those preferring cereals, intake of total energy, protein, fat, calcium, and certain vitamins was low compared to other patterns. The preferred vegetables pattern was advantageous for the intake of most vitamins and certain minerals. The preferred dairy products pattern was of great advantage
Table 4. Present illness in each dietary pattern.

\begin{tabular}{cccccc}
\hline & & $\begin{array}{c}\text { Vegetables } \\
\text { products }\end{array}$ & $\begin{array}{c}\text { Dairy } \\
\text { products } \\
\text { pattern }\end{array}$ & $\begin{array}{c}\text { Beverages } \\
\text { pattern }\end{array}$ & $\begin{array}{c}\text { Cereals } \\
\text { pattern }\end{array}$ \\
\hline $\begin{array}{c}\text { Absence of } \\
\text { illness }\end{array}$ & $n$ & 19 & 18 & 5 & 17 \\
$\begin{array}{c}\text { Presence of } \\
\text { illness }\end{array}$ & $n$ & 14 & 8 & 5 & 18 \\
& & & & &
\end{tabular}

Relationship between present illness and dietary patterns was investigated by $\chi^{2}$ test. Presence or absence of illness did not differ among the four dietary patterns $\left(\chi^{2}\right.$ $(\mathrm{df}=3)=2.8, p=0.42)$.

for calcium intake, approaching the recommended dietary allowance (9). Salt intake was $6-7 \mathrm{~g}$ on the average in all patterns.

Survival analysis

Figure 1 depicts the survival curve for each dietary pattern. Survival of those that preferred dairy products was significantly higher than those that preferred beverages $(p=0.048)$, and additionally tended to be higher than that for the two other patterns. Survival of those that preferred cereals was similar to that for those that preferred vegetables. As shown in Fig. 2, the survival curve for men was similar to that for women $(p=0.68)$. Survival curves did not differ significantly between centenarians with major diseases and those without illness $(p=0.44$, Fig. 3).

\section{DISCUSSION}

Variation in dietary habits has been linked to lifestyle-related diseases such as diabetes mellitus. A questionnaire survey of approximately 3,000 centenarians in Japan suggested that they paid particular attention to daily nutrition for longevity (10). We found a dietary preference for dairy products in Tokyo-area centenarians (1). Is there any relationship between dietary patterns and further survival in centenarians?

The present study suggests that centenarians who prefer dairy products tend to have greater longevity than those who prefer other dietary patterns. However, clinical variables, such as nutritional status, tended to 
Table 5. Nutritional evaluation of each cluster in centenarians.

\begin{tabular}{|c|c|c|c|c|c|}
\hline & $\begin{array}{l}\text { Vegetables } \\
\text { pattern }\end{array}$ & $\begin{array}{l}\text { Dairy products } \\
\text { pattern }\end{array}$ & $\begin{array}{l}\text { Beverages } \\
\text { pattern }\end{array}$ & $\begin{array}{l}\text { Cereals } \\
\text { pattern }\end{array}$ & $\begin{array}{l}\text { Reference* } \\
\text { value }\end{array}$ \\
\hline Energy (kJ) & $5,130 \pm 1,075^{\mathrm{a}}$ & $4,653 \pm 967$ & $5,326 \pm 1,628$ & $4,318 \pm 820^{\mathrm{a}}$ & $5,400-6,700^{\dagger}$ \\
\hline Protein $(\mathrm{g})$ & $48.6 \pm 12.0^{\mathrm{b}}$ & $44.4 \pm 11.1$ & $50.1 \pm 14.3^{c}$ & $38.9 \pm 8.2^{b, c}$ & $55-65$ \\
\hline Fat $(\mathrm{g})$ & $33.9 \pm 11.3^{\mathrm{d}}$ & $32.8 \pm 10.3^{\mathrm{e}}$ & $31.7 \pm 12.1$ & $24.8 \pm 7.7^{\text {d,e }}$ & \\
\hline Carbohydrate (g) & $176.7 \pm 37.5$ & $155.9 \pm 34.5$ & $176.0 \pm 61.7$ & $156.8 \pm 31.4$ & \\
\hline Energy from fat $(\%)$ & $25.0 \pm 5.2^{f}$ & $26.7 \pm 5.7^{\mathrm{g}}$ & $23.2 \pm 6.9$ & $21.6 \pm 5.3^{f, g}$ & $20-25$ \\
\hline Vitamin A (IU) & $2,107 \pm 1,052^{\mathrm{h}}$ & $1,677 \pm 714$ & $1,508 \pm 601$ & $1,282 \pm 764^{\mathrm{h}}$ & $1,800-2,000$ \\
\hline Vitamin $B_{1}(\mathrm{mg})$ & $0.67 \pm 0.21^{\mathrm{i}}$ & $0.57 \pm 0.20$ & $0.70 \pm 0.45^{\mathrm{j}}$ & $0.50 \pm 0.20^{\mathrm{i}, \mathrm{j}}$ & $0.8-1.1$ \\
\hline Vitamin $B_{2}(\mathrm{mg})$ & $0.93 \pm 0.23^{k}$ & $1.05 \pm 0.28^{1}$ & $1.00 \pm 0.31^{\mathrm{m}}$ & $0.62 \pm 0.19^{\mathrm{k}, \mathrm{l}, \mathrm{m}}$ & $1.0-1.2$ \\
\hline Vitamin C (mg) & $99 \pm 35^{n, o}$ & $79 \pm 56$ & $68 \pm 37^{\mathrm{n}}$ & $60 \pm 27^{\circ}$ & 100 \\
\hline Vitamin D (IU) & $206 \pm 155$ & $187 \pm 177$ & $264 \pm 111$ & $193 \pm 138$ & 100 \\
\hline Vitamin E (mg) & $6.1 \pm 1.8^{\mathrm{p}, \mathrm{q}}$ & $4.9 \pm 1.7^{p}$ & $5.2 \pm 2.0$ & $4.4 \pm 1.2^{\mathrm{q}}$ & $8-10$ \\
\hline Calcium (mg) & $423 \pm 126^{\mathrm{rs}}$ & $571 \pm 175^{\mathrm{rt}, \mathrm{u}}$ & $429 \pm 181^{\mathrm{t}, \mathrm{v}}$ & $285 \pm 102^{s, u, v}$ & 600 \\
\hline Phosphorus (mg) & $725 \pm 184^{w}$ & $772 \pm 193^{x}$ & $741 \pm 224^{y}$ & $539 \pm 131^{w, x, y}$ & 700 \\
\hline Iron (mg) & $7.2 \pm 2.1^{\mathrm{z}, \mathrm{A}}$ & $5.8 \pm 2.0^{z}$ & $6.6 \pm 2.3$ & $5.3 \pm 1.4^{\mathrm{A}}$ & 10 \\
\hline Salt $(\mathrm{g})$ & $7.0 \pm 2.5$ & $6.0 \pm 2.3$ & $7.1 \pm 3.1$ & $6.3 \pm 2.4$ & 10 \\
\hline Potassium (mg) & $1,923 \pm 580^{\mathrm{B}}$ & $1,840 \pm 536^{\mathrm{C}}$ & $1,808 \pm 629^{\mathrm{D}}$ & $1,341 \pm 408^{\mathrm{B}, \mathrm{C}, \mathrm{D}}$ & 2,000 \\
\hline Magnesium (mg) & $172 \pm 53^{\mathrm{E}}$ & $162 \pm 45$ & $161 \pm 56$ & $130 \pm 35^{\mathrm{E}}$ & $240-280$ \\
\hline Copper (mg) & $0.83 \pm 0.28^{\mathrm{F}}$ & $0.64 \pm 0.20^{\mathrm{F}}$ & $0.71 \pm 0.30$ & $0.68 \pm 0.15$ & $1.4-1.6$ \\
\hline Zinc (mg) & $5.7 \pm 2.1^{\mathrm{G}}$ & $4.9 \pm 1.3$ & $5.2 \pm 1.5$ & $4.5 \pm 1.0 \mathrm{G}$ & $9-10$ \\
\hline
\end{tabular}

Values are presented as the mean \pm SD. Means were compared by ANOVA followed with Scheffe's test. Superscripts indicate that differences of values between the same symbols are statistically significant (e.g., energy intake between the vegetables pattern and cereals pattern show a significant difference, $p<0.05)$. a, c, e, f, j, n, y, D, F, G: $p<0.05, \mathrm{~b}, \mathrm{~d}, \mathrm{i}, \mathrm{p}, \mathrm{t}, \mathrm{v}, \mathrm{z}, \mathrm{E}$ : $p<0.01, \mathrm{~g}, \mathrm{~h}, \mathrm{k}, \mathrm{l}, \mathrm{m}, \mathrm{o}, \mathrm{q}, \mathrm{r}, \mathrm{s}, \mathrm{u}, \mathrm{w}, \mathrm{x}, \mathrm{A}, \mathrm{B}, \mathrm{C}: p<0.001$.

* Recommended dietary allowance for Japanese elderly (cited from ref. 9).

${ }^{\dagger}$ Assumes a light level of physical activity.

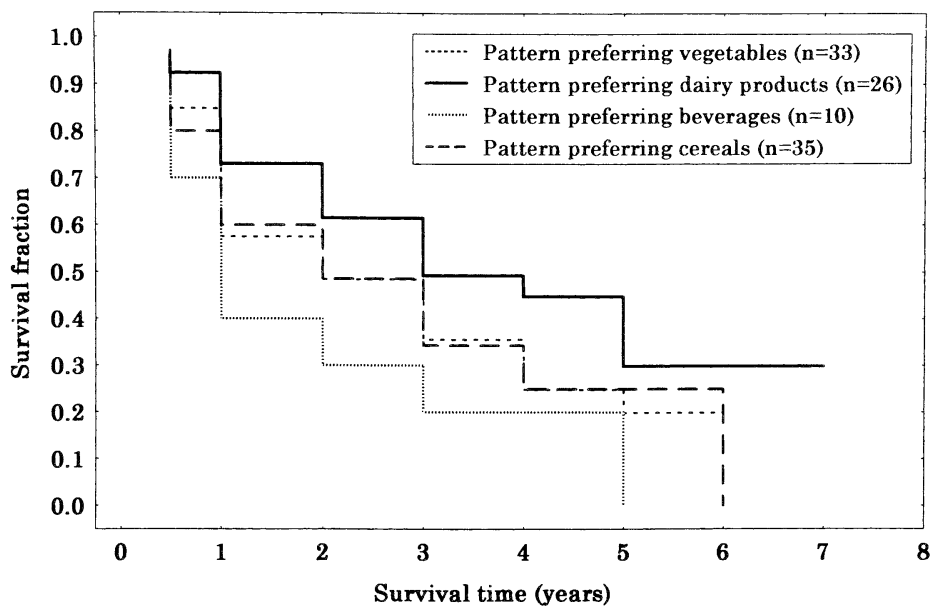

Fig. 1. Survival curve in each dietary pattern.

differ between the four dietary patterns. Therefore, it is not definitive that the above-mentioned result is directly due to the preferential intake of dairy products. For instance, if a dietary pattern included more under-nourished subjects, mortality for that pattern might be higher. As for ADL and cognitive function, neither was different between the four dietary patterns. Although nutritional status was not evaluated for all subjects, serum albumin concentrations in the pattern preferring beverages tended to be lower as compared to the other patterns. According to our previous study (11), serum albumin concentrations have a maximal influence on further survival in centenarians; subjects with a low serum albumin concentration were at higher risk of death during follow-up. A tendency toward hypo-albuminemia in the pattern preferring beverages might be partly associated with increased mortality. There was a male bias in the pattern of beverage consumption. Since women are known to live longer than men, such a gender difference might influence the survival analysis. However, in the present study, the survival curve of men was similar to that of women. In people who have reached the age of $100 \mathrm{y}$, gender may have a minimal influence on survival. With respect to present illness, only for the pattern that preferred dairy products, did centenarians without major disease far exceed 


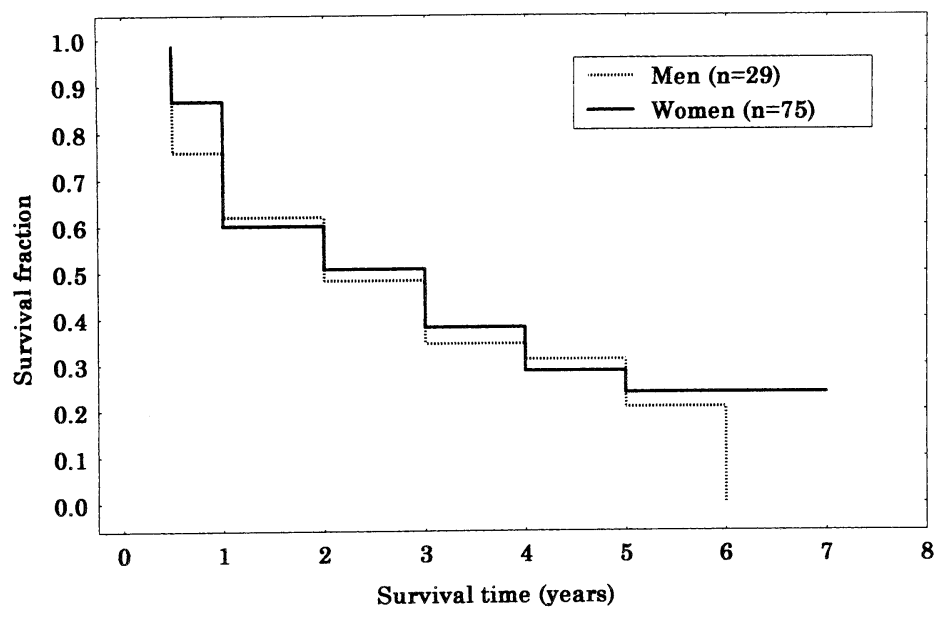

Fig. 2. Survival curve in men and women.

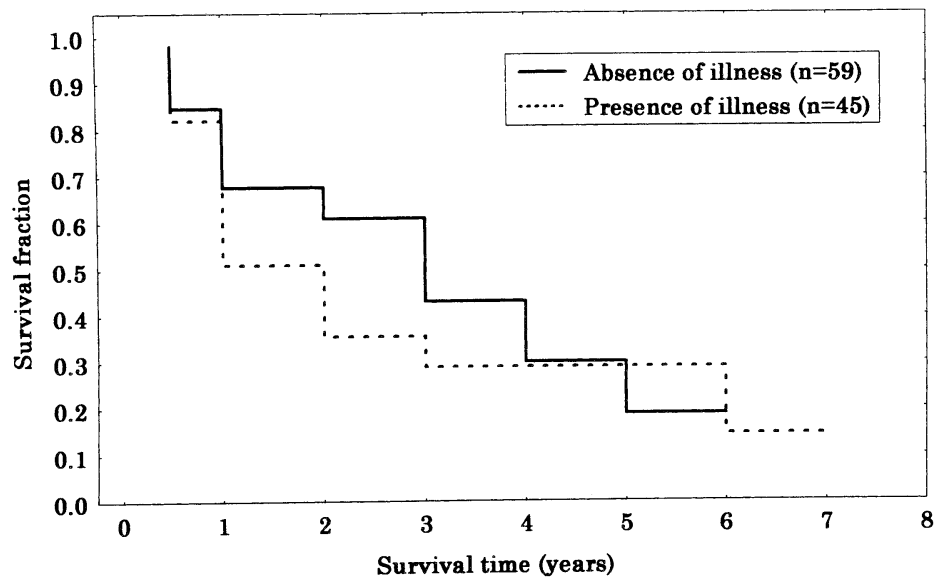

Fig. 3. Survival curve in centenarians with and without diseases.

those with overt disease. During the first 3 y of followup, survival for centenarians with illnesses tended to be lower than for those that were not ill. Therefore, a high ratio of healthy to unhealthy centenarians observed in those that preferred dairy products might contribute to increased survival.

There are previous studies on the relationship between dairy products and life span. Some have reported that dairy products are associated with increased survival (12), while some have referred to their relation to increased mortality (13). The present study supports the belief that dairy products are associated with increased survival. Of the dairy products, milk and yogurt are rich in calcium and vitamin $\mathrm{B}_{2}$ (14); calcium has an antihypertensive effect (15) and a prophylactic action against osteoporosis, while vitamin $\mathrm{B}_{2}$ protects tissues from oxidative injury and decreases carcinogen-DNA binding (16). In addition, dairy products might include unknown factors favoring longevity. In the present study, centenarians consumed milk and yogurt as dairy products. This may account for the relationship that a dietary pattern of dairy products will increase survival.

The present study has some limitations. First, we examined only centenarians living in the Tokyo metropolitan area, from whom informed consent was obtained; this group might not be representative of all Japanese centenarians. However, dietary data of our centenarians were not different from those of a survey by Uwagawa et al. (8), reflecting dietary practices in centenarians from all areas of Japan. Second, for survival data, we depended on residence registration. We therefore could plot survival only crudely. Future studies of survival should incorporate more direct observations. Third, we did not analyze diet data using the latest Japanese Food Composition Table (5th ed.). We utilized only the 4 th edition at the time of the initial examination, and also considered that our other paper based on the 4 th edition had already been reported (1).

\section{Acknowledgments}

We acknowledge the assistance of Mr. H. Inagaki, Ms. Y. Masui, Mr. K. Kitagawa, Ms. Y. Kanno, Ms. J. Fujimori, and Ms. Y. Abe in performing the examinations of the centenarians. This work was partially supported by a grant for the multidisciplinary study of centenarians and international comparison (chief researcher, Nobuyoshi Hirose) sponsored by the Ministry of Health, Labor, and Welfare, Japan.

\section{REFERENCES}

1) Shimizu K, Noji H, Takeda S, Hirose N, Gondo Y, Konishi K. 2002. Dietary preferences in Japanese cente- 
narians favoring dairy foods. Geriatrics Gerontol Int $\mathbf{2}$ : 187-192.

2) Shibata H, Nagai H, Haga H, Yasumura S, Suzuki T, Suyama Y. 1992. Nutrition for the Japanese elderly. Nutr Health 8: 165-175.

3) Arai Y, Hirose N, Yamamura K, Shimizu K, Takayama M, Ebihara Y, Osono Y. 2001. Serum insulin-like growth factor-1 in centenarians: implication of IGF-1 as a rapid turnover protein J Gerontol 56A: M79-M82.

4) Hughes CP, Berg L, Danziger WL, Cohen LA, Martin RL. 1982. A new clinical scale for the staging of dementia Br J Psychiat 140: 566-572.

5) Ministry of Science and Technology. 2000. Japanese Food Composition Table, 4th ed. (in Japanese) (Note: the 5 th edition is now available).

6) MacQueen JB. 1967. Some methods of classification and analysis of multivariate observations. Proc. of 5th Berkeley Symposium on Math. Stat. and Prob., p 281-297.

7) Kaplan EL, Meier P. 1958. Nonparametric estimation from incomplete observations. I Am Stat Assoc 53: 457-481.

8) Uwagawa S, Saito R, Tomabechi K. 1992. Nationwide survey of intake of nutrients and proportional intake of food groups among centenarians. Jpn J Nutr 50: 227-235. (in Japanese with English summary).
9) Ministry of Health and Welfare. 1999. National Nutrition Survey (in Japanese).

10) Japanese Health Promotion and Fitness Foundation. 1994. A Survey of Welfare and Health for Oldest Old (in Japanese).

11) Shimizu K, Hirose N, Arai Y, Gondo Y, Wakida Y. 2001. Determinants of further survival in centenarians. Geriatrics Gerontol Int 1: 14-17.

12) Fortes C, Forastiere F, Farchi S, Rapti E, Pastori G, Perucci CA. 2000. Diet and overall survival in a cohort of very elderly people. Epidemiology 11: 440-445.

13) Trichopoulou A, Kouris-Blazos A, Wahlqvist M. L, Gnardellis C, Lagiou P, Polychronopoulos E, Vassilakou T, Lipworth L, Trichopoulos D. 1995. Diet and overall survival in elderly people. B M J 11: 1457-1460.

14) Krogh V, Freudenheim JL, D'Amicis A, Scaccini C, Sette S, Ferro-Luzzi A, Trevisan M. 1993. Food sources of nutrients of elderly Italians. Int J Epidemiol 22: 869-877.

15) Garcia-Palmieri MR, Costas R, Cruz-Vidal M. 1984. Milk consumption, calcium intake and decreased hypertension in Puerto Rico. Hypertension 6: 322-328.

16) Pancreker J, Krishnaswamy K, Jagadeesan V. 1993. Effects of riboflavin deficiency and riboflavin administration on carcinogen-DNA binding. Food Chem Toxicol 31: 745-750. 